UDK 546.19:543.422.3

\title{
RAZVOJ METODE ZA SPEKTROFOTOMETRIJSKO ODREĐIVANJE ARSENA
}

\section{Development of a method for the spectrophotometric determination of arsenic}

\author{
Azra Tahirović $^{1}$, Amira Čopra-Janićijević ${ }^{2}$, Kurt Kalcher ${ }^{3}$
}

\begin{abstract}
A simple and inexpensive method for the determination of arsenic at low ppb levels was developed. The method is based on reduction of arsenite and arsenate in acidic reaction medium to the formation of hydride from sample solution, and its reaction with mercury bromide. Mercury bromide was impregnated on a solid support (filter paper), and formation and detection of a yellow-brownish product was performed spectrophotometrically by using an instrument for field determination of arsenic, Supralab FD. Amidosulfonic acid was used to adjust acidity of the solutions, and reduction of arsenic compounds was done by sodium borohydride. The method was used for the determination of arsenic in soil samples after digestion.

The accuracy of the method was determined by analysis of a soil sample reference material (SRM 2710), and by an interlaboratory comparison. Detection limit of the method is $0,06 \mu \mathrm{g} \mathrm{As} / \mathrm{dm}^{3}$ with limit of quantification of $0,2 \mu \mathrm{g} \mathrm{As} / \mathrm{dm}^{3}$.
\end{abstract}

Key words: arsenic, hydride generation, spectrophotometry, forest soil.

\section{Izvod}

Razvijena je jednostavna i jeftina metoda za određivanje arsena u niskom ppb području. Metoda je zasnovana na redukciji arsenita i arsenata u kiseloj reakcionoj sredini do gasovitog produkta hidrida arsena, arsina i njegovoj reakciji sa živa(II) bromidom. Živa(II) bromid je impregniran na čvrsti nosač (filter papir), a formiranje i detekcija žuto-smeđeg produkta je vršena spektrofotometrijski, upotrebom instrumenta za terensko određivanje arsena, Supralab FD. Za podešavanje kiselosti rastvora korištena je amidosulfonska kiselina, a redukcija arsena je vršena natrij borhidridom.

Metoda je korištena $u$ određivanju arsena u uzorcima zemljišta nakon digestije. Validacija metode je izvršena upotrebom standardnog referentnog materijala (SRM 2710) i interlaboratorijskom komparacijom analizom sa ICP-MS. Limit

\footnotetext{
${ }^{1}$ Šumarski fakultet Univerziteta u Sarajevu - Faculty of Forestry, University of Sarajevo

${ }^{2}$ Prirodno-matematički fakultet Univerziteta u Sarajevu - Faculty of Science, University of Sarajevo

${ }^{3}$ Institut za hemiju Karl - Franzens Univerziteta, Graz, Austrija - Institute for Chemistry, Karl-Franzens University, Graz, Austria
} 
detekcije razvijene metode je $0,06 \mu \mathrm{g} A s / \mathrm{dm}^{3}$ sa limitom kvantifikacije od 0,2 $\mu \mathrm{g}$ $\mathrm{As} / \mathrm{dm}^{3}$.

Ključne riječi: arsen, hidridno generiranje, spektrofotometrija, šumsko zemljište

\section{UVOD - Introduction}

Jedinjenja arsena su široko zastupljena u prirodi, a pojavljuju se kao rezultat odvijanja prirodnih procesa i antropogenih aktivnosti. Dugo vremena ime arsen je bilo povezano sa terminom otrov (CULLEN I REIMER, 1989). Danas je poznato da su anorganska jedinjenja arsena, kao što su arsenit i arsenat, najtoksičnije specije arsena. Metilirana jedinjenja arsena kao što su monometilarsonska kiselina (MMA), dimetilarsinska kiselina (DMA) su manje toksična i prisutna su u prirodi zajedno sa anorganskim jedinjenjima arsena (ADRIANO, 1986; SEILER I DR., 1994). Prirodni izvori arsena u tlima su uglavnom oksisoli i minerali koji sadrže sumpor. Koncentracija arsena u tlima iznosi prosječno $7 \mathrm{mg} / \mathrm{kg}$, a u područjima intenzivne upotrebe pesticida, herbicida i defolijanata, kao i okolini rudnika i poljoprivrednim zemljištima može se kretati i do $1000 \mathrm{mg} / \mathrm{kg}$ (NORMAN, 1998; AlLOWAY, 1995; PENDIAS I PENDIAS, 1984). Preporuka Evropske zajednice je da nivo arsena u tlu ne bi trebao prelaziti $20 \mathrm{mg} / \mathrm{kg}$ (AlLOWAY 1995).

Spektrofotometrija, atomska apsorpciona i emisiona spektroskopija, masena spektrometrija, neutronska aktivacijska analiza i elektrohemijske metode se koriste $\mathrm{u}$ određivanju arsena u različitim vrstama uzoraka (SCHENK, 1989; FRESENIUS I DR., 1988; VANDECASTLEELE I DR., 1993).

Za određivanje arsena korištene su različite vrste atomske spektroskopije: plamena (FAAS), elektrotoplinska (GFAAS), kao i tehnika hidridnog generiranja u kombinaciji sa atomskom apsorpcionom spektroskopijom (HG AAS). Prve dvije metode kao nedostatak imaju izražen efekat matriksa iako se GF AAS metoda odlikuje visokom osjetljivošću sa limitom detekcije u sub- $\mu \mathrm{g} / \mathrm{dm}^{3}$ koncentracijskom području. HG AAS se zasniva na formiranju volatilnog hidrida ispitivanog elementa, te se anorganski arsen može reducirati do hidrida sa natrij borhidridom. Danas se HG AAS koristi u obliku protočnog hidridnog generiranja kombinovanog sa tehnikom protočnog ubrizgavanja $\mathrm{u}$ određivanju arsena. Tehnikom hidridnog generiranja izbjegava se efekat matriksa, te se snižava limit detekcije metode do $0,25 \mathrm{mg} / \mathrm{dm}^{3}$ (VANDECASTEELE I DR., 1993; HASWELL, 1991). Ova metoda se naročito koristi u specijacijskoj analizi arsena (WELZ, 1998). Određivanje anorganskog arsena je izvedeno u $6 \mathrm{M} \mathrm{HCl}$ (LOPEZ I DR., 1992; TORRALBA I DR., 1994), $5 \mathrm{M} \mathrm{HCl}$ (DRIEHAUS I JEKEL., 1992; AGGETT I ASPELL, 1976), 8 M perhloratnoj kiselini (SHRAIM I DR., 2000).

Atomizer indukovano spregnuta plazma (ICP) u kombinaciji sa atomskom emisionom spektroskopijom (AES) i masenom spektrometrijom (MS) daje dvije moćne metode za određivanje izuzetno malih koncentracija arsena u prirodnim uzorcima, kao i za multielementno određivanje velikog broja različitih elemenata. 
Međutim, nedostatak ovih metoda jeste njihova izuzetno visoka cijena instrumenata, kao i potreba za obučavanjem osoblja za rad.

Zbog toga je razvoj i uvođenje novih metoda visoke osjetljivosti $i$ selektivnosti u analizi malih koncentracija ispitivanog analita od prioritetnog značaja (WILLARD IDR., 1981; BEAUCHEMIN, 1998).

U radu je opisan razvoj metode za određivanje ukupnog arsena upotrebom jednostavnog uređaja za terensko određivanje. Metoda je zasnovana na spektrofotometrijskom određivanju arsena redukcijom anorganskog arsena u rastvoru amidosulfonske kiseline s borhidridom i optičkoj detekciji obojenog molekulskog kompleksa koji nastaje kao rezultat reakcije arsina i živa(II) bromida imregniranog na filter papiru. Sama reakcija predstavlja modifikaciju Gutzejtove reakcije, koja se inače koristi za kvalitativno određivanje arsena i detaljno je opisana u literaturi (BERMAN, 1991). U radu je prikazana optimizacija analitičke procedure i metoda je primijenjena u određivanju arsena u uzorcima zemljišta nakon mineralizacije uzoraka. Dobiveni rezultati su validirani interlaboratorijskom komparacijom rezultata primjenom druge analitičke metode (ICP-MS), kao i upotrebom referetnog standardnog materijala (NIST Montana Soil 2710).

\section{MATERIJAL I METODE - Materials and methods}

\section{Instrumentacija - Instrumentation}

Mjerenja su vršena instrumentom SupraLab FD ((HeloTec, Kaisdorf bei Graz, Austria) (MODEREGGER 1998, STEC I DR. 2006). Uređaj je konstruisan u laboratoriji prof. dr. Kurt Kalchera, (Institut za analičku hemiju, Karl-Franzens univerzitet) i predstavlja modifikaciju instrumenta namijenjenog za određivanje arsena u vodi (MODEREGGER, 1998). Formiranje arsina je izvođeno u arsinskom generatoru (Erlenmayer boca, 100 $\mathrm{cm}^{3}$ ), koji je bio povezan sa detektorskom ćelijom preko plastičnog adaptera. Tijelo uređaja je napravljeno od polivinil hlorida. Plastični adapter je bio opremljen sa dva filter papira (Macherey-Nagel; Duren, Germany) impregnirana olovo(II) acetatom radi uklanjanja hidrogen sulfida koji se može formirati tokom reakcije stvaranja arsina iz rastvora uzoraka. $\mathrm{U}$ adapter je bila smještena vata $(0,1 \mathrm{~g})$ između sulfidnog absorbera $\mathrm{i}$ detektorske ćelije kako bi se uklonile eventualno prisutne aerosoli vode iz gasne smjese.

Postavka instrumenta je prikazana na slici 1. Osnovni dio uređaja je detektorska ćelija koja sadrži svjetlosno emitirajuću diodu (LED, $\lambda \max =470 \mathrm{~nm}$ ), fotodiodu $(\lambda \max =550 \mathrm{~nm})$, filter papir (Macherey-Nagel; Duren, Germany, 13mm) impregniran živa(II) bromidom, koji su postavljeni linijski. Arsin, stvoren tokom hidridnog generiranja prolazi kroz filter papir, dajući produkt žuto-smeđe boje. Intenzitet boje na papiru detektira se optički sa svjetlosno emitirajućom diodom i fotodiodom $\mathrm{u}$ transmisionom modu. Fotodioda transformira intenzitet svjetlosti linearno u struju (fotostruja). S obzirom na to da je fotostruja u niskim mikro i makro 
amperima, signal se mora pojačati prije digitalizacije. Nakon toga signal se prenosi kao napon do analogno-digitalnog pretvarača (ADC) i dobiveni binarni podaci se prenose do računara odgovarajućim softverom.

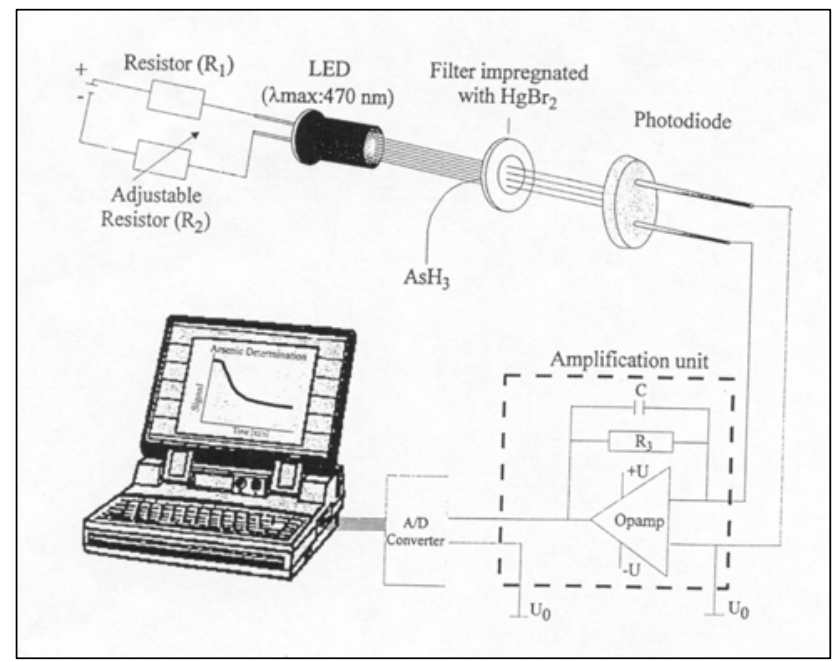

Slika 1. Šema uređaja (MODEREGGER, 1998)

Picture 1. Scheme of the instrument (MODEREGGER, 1998)

\section{Princip rada}

Filter papir impregniran živa(II) bromidom postavljen je u detektorsku ćeliju. Intenzitet svjetla sa LED-a je podešen preko promjenjivog otpornika $\left(\mathrm{R}_{2}\right.$ na slici 1$)$ na način da izlazni signal pojačivača fotodiode odgovara vrijednosti 1000 bita. Određena količina otopine uzorka $\left(50 \mathrm{~cm}^{3}\right)$ je prebačena u reakcionu posudu u kojoj je smješten magnet obložen teflonom. Plastični adapter zajedno sa detektorskom ćelijom je postavljen na hidridni generator (reakcionu posudu), a istovremeno se sa odgovarajućim softverom vršilo snimanje signala. Jedan bit odgovara vrijednosti potencijala od $4 \mathrm{mV}$.

Sistem za mikrovalno rastvaranje uzoraka - Microwave digestion system

Sistem za mikrovalno rastvaranje (MS-ETHOS 1600 Microwellen Laborsystem, Leutkirch, Germany) je korišten za rastvaranje uzoraka zemljišta.

\section{Reagensi - Reagents}

Sve hemikalije i reagensi korišteni u radu bili su analitičkog stepena čistoće ili višeg, a dobavljeni su od proizvođača Fluka i Merck. Za pripremanje svih rastvora korištena je ultra čista voda, pripremljena dvostrukom destilacijom u kvarcnom 
sistemu i prečišćena na ionoizmjenjivaču model NANOpure, Barnstead ( Boston, USA; 18 ' $\Omega \mathrm{cm})$.

Standardni rastvori As(III) i As(V) su pripremljeni rastvaranjem odgovarajuće količine natrij metaarsenita $i$ dinatrij hidrogenarsenata $u$ ultra čistoj vodi $u$ koncentracijama od $1000 \mathrm{mg} / \mathrm{dm}^{3}$. U standardni rastvor arsenita je dodana askorbinska kiselina u koncentraciji $0,1 \mathrm{~mol} / \mathrm{dm}^{3}$, kako bi se spriječila eventualna oksidacija arsenita u arsenat. Rastvori As(III) i As(V) manje koncentracije $\left(1 \mathrm{mg} / \mathrm{dm}^{3}\right)$ su pripremani dnevno, odgovarajućim razblaživanjem standardnih rastvora, a od njih su dalje pripremani radni rastvori.

Amidosulfonska kiselina je korištena u obliku tableta. Jedna tableta je sadržala $1,7800 \mathrm{~g}$ čiste kiseline. Natrij borhidrid je korišten u obliku tableta. Jedna tableta je sadržala 0,300 g natrij borhidrida u $5 \mathrm{~g}$ natrij hlorida.

Supra pure nitratna kiselina (65\%) i hidrogen peroksid $(30 \%)$ su korišteni za mineralizaciju uzoraka zemljišta.

Referenti materijal Montana Soil 2710 (US Department NIST, Gauthersburg) korišten je u validaciji metode.

Posuđe korišteno $u$ radu je prije upotrebe temeljito očišćeno potapanjem u zlatotopci ili nitratnoj kiselini (1:1), dva-tri dana, nakon čega su posude isprane ultra čistom vodom.

\section{Procedure - Procedures}

\section{Impregnacija filter papira sa živa(II) bromidom}

Filter papiri dimenzija 80 × $98 \mathrm{~mm}$ su uronjeni u rastvor živa(II) bromida $(10 \% \mathrm{~m} / \mathrm{v}$ u acetonu) deset minuta. Tokom postupka impregnacije posuda je pokrivena staklenim poklopcem i povremeno je vršeno mehaničko miješanje rastvora u mraku. Nakon impregnacije, filter papiri su prebačeni u plastične posude, gdje su sušeni 15 minuta na sobnoj temperaturi. Nakon sušenja, impregnirani filter papiri su isječeni do dimenzija prečnika $13 \mathrm{~mm}$ specijalnim kalupom kružnog oblika i smješteni u odgovarajuće kutije do upotrebe.

\section{Impregnacija filter papira sa olovo(II) acetatom}

Filter papiri su bili uronjeni u vodeni rastvor olovo(II) acetata $(10 \% \mathrm{~m} / \mathrm{m})$ pet minuta, nakon čega su prebačeni u sušnicu gdje su sušeni na $40^{\circ} \mathrm{C}$ najmanje 12 sati. Impregnirani filter papiri su zatim smješteni u eksikator iznad fosfor pentoksida. Nakon sušenja u eksikatoru, filter papiri su isječeni specijalnim kalupom kružnog oblika (prečnik $18 \mathrm{~mm}$ ) i smješteni u odgovarajuće kutije do upotrebe.

\section{Uzorkovanje i priprema uzoraka - Soil sampling and sample preparation}

U ispitivanjima su korišteni uzorci šumskog zemljišta (smeđe šumsko zemljište) sa područja centralne Bosne. Odabrano mjesto uzorkovanja nalazi se $u$ 
vareškom regionu i predstavlja šumsko-industrijsko područje. Uzorci su uzeti na lokalitetu Veovača, Šumsko-gospodarska jedinica "Gornja Stavnja", u neposrednoj blizini rudnika barita, galenita i sfalerita. Na lokalitetu je označena eksperimentalna ploha veličine $20 \times 20 \mathrm{~m}$. Reprezentativni uzorak je dobiven miješanjem više pojedinačnih uzoraka. Uzorkovanje je vršeno na dubini $12-22 \mathrm{~cm}$.

U laboratoriji su uzorci sušeni na zraku, na sobnoj temperaturi i prosijani na sito promjera $2 \mathrm{~mm}$. Nakon homogenizacije, uzorci su prosijani na mikrosito, ponovo homogenizirani i pohranjeni $u$ frižider na $4^{0} \mathrm{C}$ do upotrebe.

\section{Procedure - Procedures}

\section{Određivanje ukupnog anorganskog arsena}

U Erlenmayer posudu $\left(100 \mathrm{~cm}^{3}\right)$ dodana je određena količina As(III) ili As(V) nakon čega je podešen volumen rastvora razblaživanjem na $50 \mathrm{~cm}^{3}$. Zatim su u reakcionu posudu dodane dvije tablete amidosulfonske kiseline i jedna tableta natrij borhidrida. Plastični adapter u koji su smješteni filter papiri impregnirani olovo(II) acetatom i vata povezan je sa detektorskom ćelijom koja je montirana na reakcionu posudu, pri čemu je odmah započeto snimanje signala.

\section{Određivanje arsena u uzorcima}

Tri probe mase po $0,2000 \mathrm{~g}$ uzorka zemljišta su vagane u teflonske bombe od $60 \mathrm{~cm}^{3}$, a zatim je dodano $5 \mathrm{~cm}^{3}$ nitratne kiseline $(65 \%)$ i $1 \mathrm{~cm}^{3}$ hidrogen peroksida (30\%). U postupak rastvaranja je bila uključena i slijepa proba, kao i referentni material, pripremljen na identičan način kao i uzorci zemljišta. Rastvaranje uzoraka je vršeno u mikrovalnom sistemu prema odgovarajućem temperaturnom programu:

Zagrijavanje $25^{\circ} \mathrm{C}-225^{\circ} \mathrm{C}$ (10 minuta)

Rastvaranje $\quad 225^{\circ} \mathrm{C} \quad$ (27 minuta)

Hlađenje $\quad 225^{\circ} \mathrm{C}-25^{\circ} \mathrm{C} \quad(25$ minuta)

Nakon mineralizacije, rastvori su prebačeni u posude za centrifugiranje (50 $\mathrm{cm}^{3}$ ) i razblaženi ultra čistom vodom do $50 \mathrm{~cm}^{3}$. Rastvori su smješteni u frižider na $4^{\circ} \mathrm{C}$ do analize.

Određivanje arsena $\mathrm{u}$ uzorcima je izvedeno prema proceduri opisanoj za ukupni anorganski arsen. Koncentracija arsena $u$ ispitivanim uzorcima određena je primjenom vanjskih kalibracionih krivi. Test iskorištenja i efekat matriksa ispitivani su metodom standardnog dodatka. 


\section{REZULTATI - Results}

\section{Optimizacija - Optimization}

\section{Kiselost - Acidity}

Optimizacija kiselosti je vršena $u$ rastvorima As(III) i As(V) u koncentracijama od po $10 \mu \mathrm{g} / \mathrm{dm}^{3}$. Za optimizaciju je korištena amidosulfonska kiselina $\mathrm{u}$ obliku tableta. Test iskorištenja je proveden komparacijom signala samog rastvora $\mathrm{As}(\mathrm{V})$ i smjese $\mathrm{As}(\mathrm{V})$ i $\mathrm{As}(\mathrm{III})$ sa signalom rastvora $\mathrm{As}(\mathrm{III})$ iste koncentracije. Vrijednost signala As(III) $\left(\gamma=10 \mu \mathrm{g} / \mathrm{dm}^{3}\right)$ je uzeta za $100 \%$. Rezultati su prezentirani u tabeli 1 .

Tabela 1. Utjecaj amidosulfonske kiseline na hidridno generiranje arsina iz rastvora $\mathrm{As}(\mathrm{V})(10$ $\left.\mu \mathrm{g} / \mathrm{dm}^{3}\right)$ i smjese As(III) i As(V) $\left(5 \mu \mathrm{g} / \mathrm{dm}^{3}\right.$ svakog).

Table 1. Influence of amidosulfonic acid on hydride generation of arsine from solutions of $A s(V)\left(10 \mu \mathrm{g} / \mathrm{dm}^{3}\right)$ and mixtures of $A s(I I I)$ and $A s(V)\left(5 \mu \mathrm{g} / \mathrm{dm}^{3}\right.$ of each)

\begin{tabular}{|c|c|c|c|c|}
\hline $\begin{array}{c}\text { Masa amidosulfonske } \\
\text { kiseline }\end{array}$ & $\begin{array}{c}\text { Signal } \\
\text { arsenata } \\
\text { Mass of amidosulfonic } \\
\text { acid } \\
\text { (g) }\end{array}$ & $\begin{array}{c}\text { Iskorištenje } \\
\text { Recovery } \\
(\%)\end{array}$ & $\begin{array}{c}\text { Signal } \\
\text { smjese } \\
\text { Signal of } \\
\text { (Biti) }\end{array}$ & $\begin{array}{c}\text { Iskorištenje } \\
\text { Recovery } \\
(\%)\end{array}$ \\
\hline 1,7800 & $449 \pm 10$ & 94,8 & $458 \pm 11$ & 96,5 \\
\hline 3,5600 & $462 \pm 12$ & 98,0 & $468 \pm 19$ & 99,6 \\
\hline
\end{tabular}

Identičan signal je postignut za obje specije kada su korištene dvije tablete amidosulfonske kiseline, pri čemu je kiselost otopina iznosila $0,74 \mathrm{~mol} / \mathrm{dm}^{3}$.

\section{Reducent- Reductant}

Ista količina natrij borhidrida je korištena za generiranje arsina iz rastvora As(III) i As(V). Masa od 0,300 g reducenta je korištena za otopinu uzorka volumena $50 \mathrm{~cm}^{3}$. Ispitivanja su pokazala da je ova količina reducenta dovoljna za kvantitativnu redukciju arsena čak do koncentracija od $100 \mu \mathrm{gAs} / \mathrm{dm}^{3}$.

Vremenska ovisnost reakcije - Time dependence

Kako bi se utvrdilo optimalno vrijeme za izvođenje reakcije, praćena je kinetika reakcije formiranja hidrida $\mathrm{u}$ vremenskom intervalu od pet minuta.

Kriva odgovora za $\mathrm{As}(\mathrm{III})$ i $\mathrm{As}(\mathrm{V})$ na različitim koncentracijama prikazana je na grafikonu 1. 


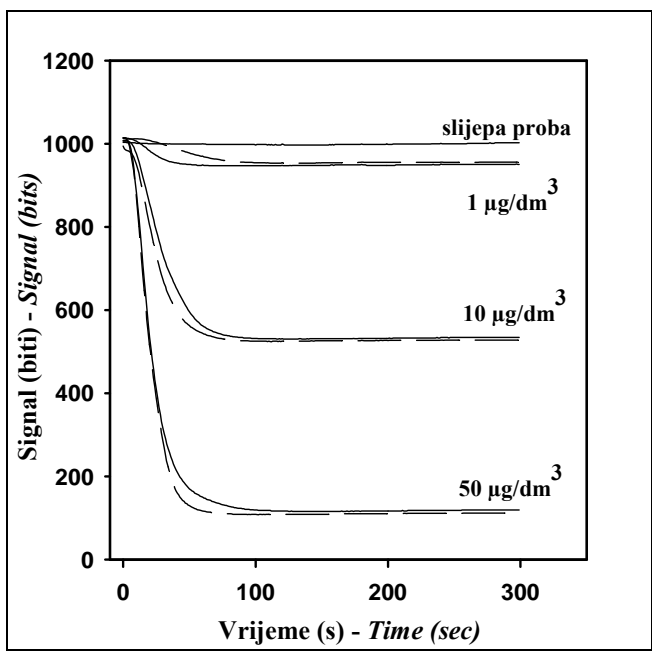

Grafikon 1. Signali As(III) (-) i As(V) (----) tokom reakcija formiranja hidrida u funkciji vremena. Graph 1. Signals of As(III) and As(V) during hydride forming reactions as a function of time.

Vrijeme od pet minuta je sasvim dovoljno za kompletnu reakciju obje specije arsena u ispitivanom koncentracijskom području.

\section{Kalibracione krive - Calibration curves}

Zavisnost signala od koncentracije arsena $u$ vodenim rastvorima As(III) i $\mathrm{As}(\mathrm{V})$ je ispitivana pod optimiziranim eksperimentalnim uslovima. Kalibracijom je podešena početna vrijednost napona fotodiode (Uo) i to promjenom intenziteta svjetlosno emitirajuće diode. Ta početna vrijednost je blizu 1000 bita, ali je uvijek malo različita. Da bi se napravila korekcija početnih vrijednosti, ukupna razlika signala $\Delta$ Uo je izračunata prema jednačini:

$$
\Delta U o=(U o-U e)^{*} \frac{1000}{U_{0}}
$$

gdje je Ue signal na kraju reakcije.

Efektivna razlika signala, $\Delta \mathrm{U}$ je korigovana za vrijednost slijepe probe $\Delta \mathrm{Uo}, \mathrm{b}$ i predstavljena je garfički kao $\Delta \mathrm{U}$ :

$$
\Delta \mathrm{U}=\Delta \mathrm{U}_{\mathrm{o}}-\Delta \mathrm{U}_{\mathrm{o}, \mathrm{b}}
$$

Grafikon 2 prikazuje zavisnost razlike signala $(\Delta \mathrm{U})$ od koncentracije $\mathrm{As}(\mathrm{III}) \mathrm{u}$ koncentracijskom području 0,2-60 $\mu \mathrm{g} / \mathrm{dm}^{3}$. Grafikon prikazuje kvazilinearno ponašanje do $8 \mu \mathrm{g} / \mathrm{dm}^{3}$, a iznad te koncentracije kriva počinje opadati. 


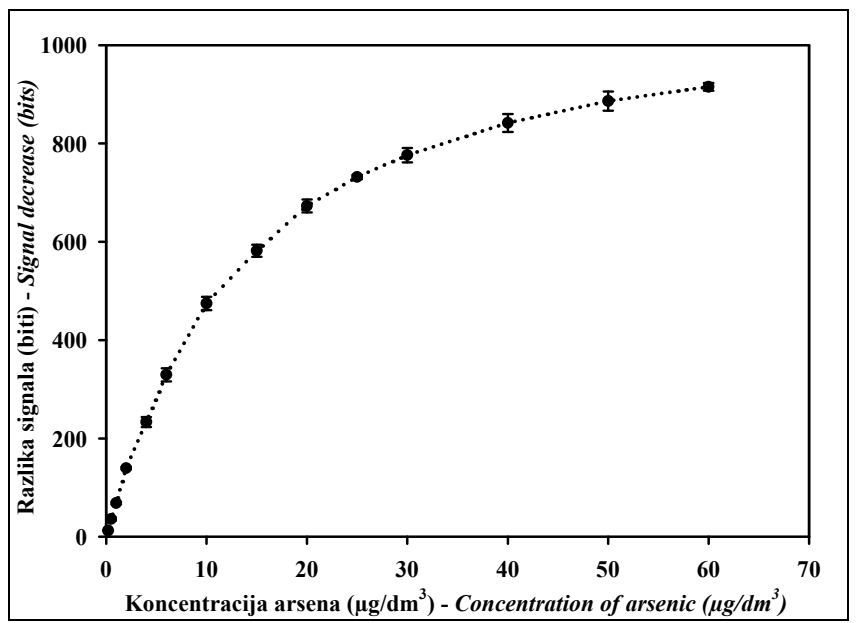

Grafikon 2. Zavisnost razlike signala $(\Delta \mathrm{U})$ od koncentracije arsena Graph 2. Dependence of the signal decrease $(\Delta U)$ on the concentration of arsenic

Kako bi se provjerio signal arsenata pod istim eksperimentalnim uslovima, vršena su mjerenja razlike signala sa različitim koncentracijama arsenata $u$ amidosulfonskoj kiselini (grafikon 3). Komparacija razlike signala $(\Delta U)$ za As(III) i $\mathrm{As}(\mathrm{V})$ je prestavljena grafički (grafikon 3).

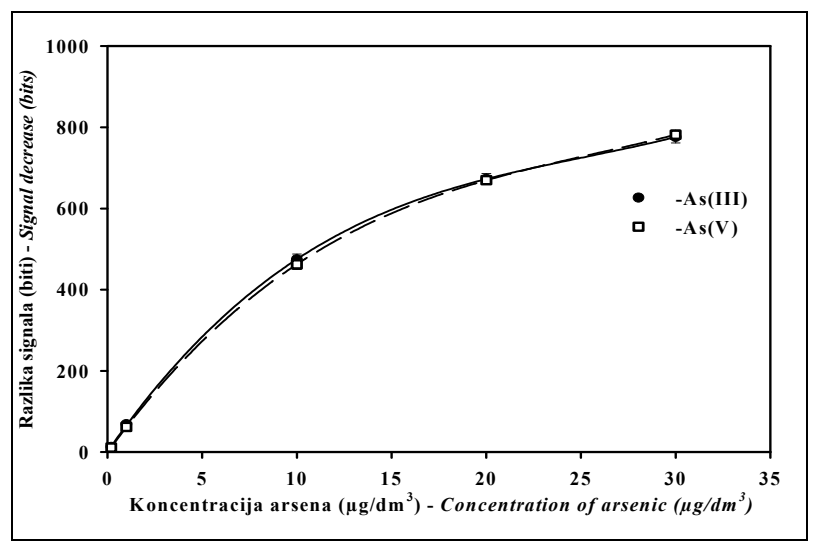

Grafikon 3. Zavisnost razlike signala $(\Delta \mathrm{U})$ od koncentracije arsenita i arsenata.

Graph 3. Dependence of signal decrease $(\Delta U)$ on the concentration of arsenite and arsenate.

Kako bi se provjerila validnost Lambert-Beerovog zakona, kriva zavisnosti razlike signala arsenita je transformirana $u$ odgovarajući oblik i prikazana kao zavisnost apsorbanse od koncentracije arsena. Apsorbansa je dobivena računski koristeći sljedeću jednačinu: 


$$
A=\log \frac{I_{0}}{I}=\log \frac{\Delta U_{0, C}-\Delta U_{0, B}}{\Delta U_{0, C}-\Delta U_{0, S}}
$$

gdje je $\Delta U$ o,b razlika signala slijepe probe; $\Delta \mathrm{Uo,c}$ razlika signala potpune reakcije sa živa(II) bromidom; $\Delta$ Uo,s razlika signala uzorka na kraju reakcije.

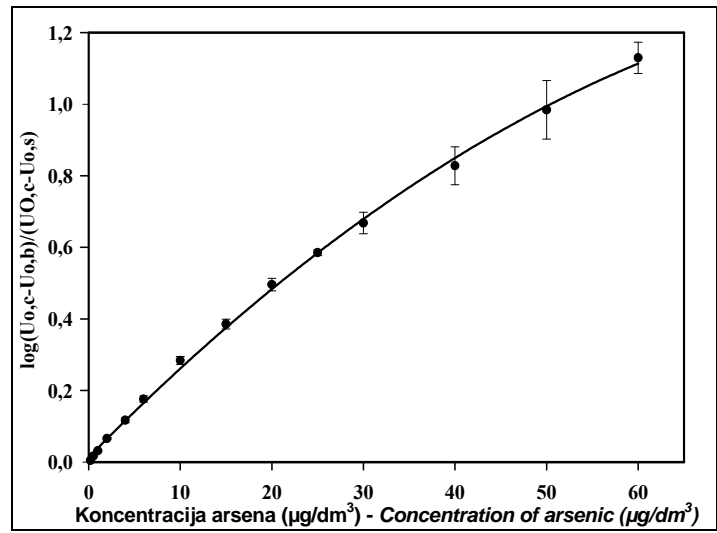

Grafikon 4. Kalibraciona kriva predstavljena kao zavisnost apsorbanse od koncentracije arsena. Graph 4. Calibration curve presented as dependence of absorbance versus arsenic concentration.

Budući da filter papir nakon kompletne reakcije živa (II) bromida i arsina može biti još transparentan za svjetlo, neophodno je odrediti radni napon fotodiode. Traženi signal za kompletnu reakciju $(\Delta U \mathrm{Uo}, \mathrm{c})$ određen je mjerenjem signala sa otopinom standarda arsena u apsolutnoj vrijednosti analita od $50 \mu \mathrm{g}$. Odgovarajući kalibracijski dijagram je predstavljen na grafikonu 4.

Kalibracijski dijagram se može koristiti za kvantifikaciju arsena u cijelom ispitivanom koncentracijskom području sa prihvatljivom preciznošću, ali najbolji rezultati se očekuju u koncentracijskom području između 0,2 i $20 \mu \mathrm{g} / \mathrm{dm}^{3}$ arsena, što se vidi na grafikonu 5 .

Kalibraciona kriva je data za koncentraciju $0-20 \mu \mathrm{g} / \mathrm{dm}^{3}$ i podaci su opisani kvadratnom funkcijom, pri čemu su dobiveni sljedeći koeficijenti: a=1,036 $10^{-3}$, $\mathrm{b}=0,031$, i $\mathrm{c}=-3,181 \cdot 10^{-4}$ sa faktorom korelacije $\mathrm{r}^{2}=0,9995$ (grafikon 5).

Relativna standardna devijacija, RSD (n=5) za $10 \mu \mathrm{g}$ As/ $/ \mathrm{dm}^{3}$ u otopini uzorka je određena i iznosi $\pm 2,8 \%$ za As(III) i $\pm 2,6 \%$ za $\mathrm{As}(\mathrm{V}) \mathrm{u}$ amidosulfonskoj kiselini. Granica kvantifikacije LOQ (najniža moguća mjerena koncentracija) je $0,2 \mu \mathrm{g}$ $\mathrm{As} / \mathrm{dm}^{3}$. Limit detekcije LOD ( $3 \sigma$ vrijednost) je izračunata koristeći standardnu devijaciju granice kvantifikacije i iznosi $0,06 \mu \mathrm{g} \mathrm{As} / \mathrm{dm}^{3}$. 


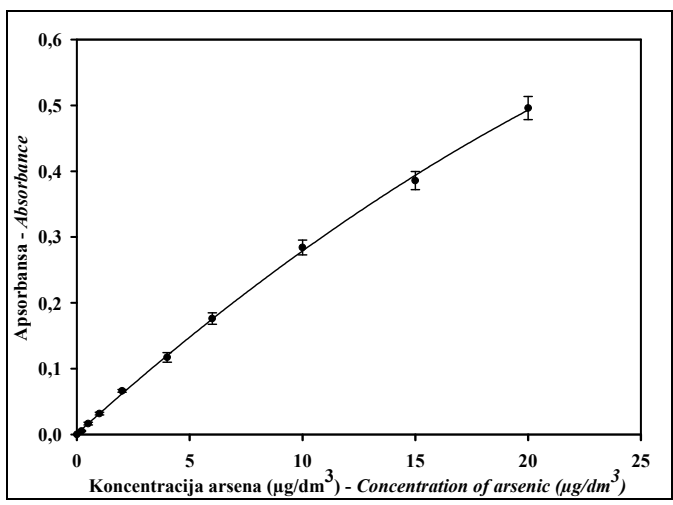

Grafikon 5. Kalibraciona kriva za kvantifikaciju arsena do $20 \mu \mathrm{g} / \mathrm{dm}^{3}$

Graph 5. Typical calibration plot for quantification of arsenic up to $20 \mu \mathrm{g} / \mathrm{dm}^{3}$

$\mathrm{Na}$ osnovu statističkih proračuna može se reći da je nova metoda sa opisanim uređajem pogodna za određivanje arsena $u$ tragovima $u$ koncentracijskom području arsena između 0,2 i $20 \mu \mathrm{g} \mathrm{As} / \mathrm{dm}^{3}$.

\section{Analiza uzorka - Sample analysis}

Tačnost metode je provjerena analizom referentnog materijala, Montana Soil (SRM 2710) i interlaboratorijskom komparacijom analizom uzoraka ICP-MS metodom. Navedene su dvije certificirane vrijednosti sadržaja arsena u referentnom materijalu. Certificirana vrijednost arsena u referentnom materijalu je iznosila $626 \pm 38$ ppm ukoliko je za rastvaranje korištena HF kiselina. Ukoliko je rastvaranje uzoraka vršeno nitratnom kiselinom, data je vrijednost mediane koja iznosi 590 ppm. Koncentracija arsena u uzorcima je određena upotrebom vanjskih kalibracionih krivih.

Test iskorištenja i efekat matriksa ispitani su metodom standardnog dodatka. Vrijednosti koncentracija arsena, dobivenih analizom uzoraka ICP-MS metodom, korišteni su za izračunavanje procenta iskorištenja. Rezultati su navedeni u tabeli 2.

Tabela 2. Komparacija vrijednosti koncentracije arsena u tri probe uzorka zemljišta i referentnom materijalu Montana Soil 2710, određenim instrumentima SupraLab FD i ICP-MS.

Table 2. Comparision of arsenic concentration in soil samples and a referent material Montana Soil 2710 determined by instruments SupraLab FD and ICP-MS.

\begin{tabular}{|c|c|c|c|}
\hline $\begin{array}{c}\text { Uzorak* } \\
\text { Sample }\end{array}$ & $\begin{array}{c}\text { Supralab FD } \\
(\mathrm{mg} / \mathrm{kg})\end{array}$ & $\begin{array}{c}\text { ICP MS } \\
(\mathrm{mg} / \mathrm{kg})\end{array}$ & $\begin{array}{c}\text { Iskorištenje (\%) } \\
\text { Recovery (\%) }\end{array}$ \\
\hline Proba 1- test 1 & $84,34 \pm 3,30$ & $89,00 \pm 0,62$ & 95,3 \\
\hline Proba 2- test 2 & $84,15 \pm 3,50$ & $92,17 \pm 0,62$ & 93,0 \\
\hline Proba 3- test 3 & $80,90 \pm 1,90$ & $88,10 \pm 0,29$ & 91,9 \\
\hline SRM 2710 & $507,50 \pm 3,50$ & $575,90 \pm 1,69$ & 88,1 \\
\hline
\end{tabular}

Rezultati su izraženi kao srednja vrijednost tri mjerenja $\pm \mathrm{SD}(\mathrm{n}=3)$.

Results are expressed as a mean value of tree replicates $\pm S D(n=3)$. 


\section{DISKUSIJA - Discussion}

Prilikom optimizacije kiselosti rastvora korištena je amidosulfonska kiselina. Prisustvo kiseline je neophodno radi odvijanja reakcije redukcije arsenita ili arsenata do hidrida. S obzirom na konstrukciju samog instrumenta, važan preduslov je jednostavno rukovanje instrumentom. Budući da je amidosulfonska kiselina čvrsta supstanca, lako se može upotrijebiti u izradi tableta odgovarajućih dimenzija, čime se olakšava sam proces određivanja, te je stoga odabrana kao najbolji izbor. Primijenjena je u obliku tablete koja je sadržala $1,7800 \mathrm{~g}$ čvrste kiseline i $0,178 \mathrm{~g}$ natrij stearata. Identičan signal je postignut za oba analita kada su dvije tablete kiseline korištene, dajući otopinama aciditet od 0,74 $\mathrm{mol} / \mathrm{dm}^{3}$ (tabela 1). Ispitivanja provedena zakiseljavanjem rastvora arsenita $\mathrm{i}$ arsenata jednom tabletom amidosulfonske kiseline pokazala su da su signali arsenata bili niži (približno za $5 \%$ ) u poređenju sa signalima arsenita.

Uobičajeni reducent koji se koristi u generiranju arsina u vodenim otopinama jeste natrij borhidrid. Osim redukcionih osobina, druga važna uloga ovoga reagensa jeste da tokom reakcije dolazi do formiranja hidrogena koji nosi hidrid do detekcione ćelije. Ispitivanjima je utvrđeno da je odabrana količina reducenta dovoljna za kvantitativnu redukciju arsena prisutnim čak i u koncentracijama većim od 100 ppb.

Utvrđeno je da je vrijeme neophodno za kompletnu reakcija arsina sa živa(II) bromidom pet minuta $u$ širokom području koncentracija arsenita $i$ arsenata. Iz grafikona 1 je uočljivo da na početku reakcije signal počinje opadati i da stepen pada signala zavisi od koncentracije analita. Što je koncentracija analita veća, veći je nagib krive, tj. brzina reakcije je veća. Nakon završetka reakcije signal dostiže konstantnu vrijednost.

Ispitivanja zavisnosti razlike signala od koncentracije arsenita su pokazala da uređaj radi dobro u koncentracijskom području $0,2-50 \mu \mathrm{g} / \mathrm{dm}^{3}$ (grafikon 2). Iznad ove vrijednosti koncentracije analita osjetljivost postaje manja tako da visoke koncentracije ne mogu biti određene sa velikom preciznošću.

Iz predočenih rezultata može se vidjeti da je ponašanje arsenita $i$ arsenata $u$ ispitivanom koncentracijskom području praktički identično (grafikon 3). To znači da je amidosulfonska kiselina odgovarajući medij za redukciju obje specije, arsenit i arsenat. Ispitivani zajednički utjecaj specija u smjesi je pokazao dobro slaganje sa pojedinačnim signalima arsenita $i$ arsenata. Dobivene vrijednosti procenta iskorištenja su se kretale između 98,6-100\%, izuzev kod niskih koncentracija arsena $(0,2$ i 1 $\mu \mathrm{g} / \mathrm{dm}^{3}$ ) gdje su dobivene vrijednosti procenta iskorištenja iznosile između 88,7-89,5 $\%$. Međutim, ako se uzme u obzir da se radi o izuzetno malim koncentracijama arsena, onda ovakva odstupanja ne predstavljaju značajnu grešku.

Kalibracijski dijagram, dobiven primjenom Lambert-Beerovog zakona $\mathrm{u}$ logaritamskom obliku je pokazao nelinearno ponašanje preko cijelog koncentracijskog područja, te dobiveni rezultati najbolje odgovaraju kvadratnoj funkciji (grafikon 5). Razlog za dobivanje ovakvih rezultata mogao bi se objasniti pojavama koje se tokom reakcije dešavaju na filter papiru (stvaranje različitih produkata s različitim količinama arsina kao i nekompletna reakcija s hidridom), a što dovodi do pojave nelinearne 
funkcije. Dobivena kalibracijska kriva se može koristiti u cijelom koncentracijskom području sa prihvatljivom preciznošću, ali su najbolji rezultati očekivani u području koncentracija analita između 0,2 i $20 \mu \mathrm{g} / \mathrm{dm}^{3}$.

Procenti iskorištenja za ispitivane uzorke zemljišta bili su između 94,0\% i $102,0 \%$ očekivanih vrijednosti signala nakon dodatka standarda poznate koncentracije (rezultati nisu prikazani). Kod komparativnih određivanja izvedenih sa ICP-MS metodom, procenti iskorištenja su bili između 92,0\% i 95,0\%, što je u dobrom slaganju sa očekivanim vrijednostima za terensku metodu. Nešto niže iskorištenje je dobiveno za referentni materijal određivanjem sa obje metode (tabela 2). Dobivene manje vrijednosti koncentracija sa uređajem za terensko određivanje mogu se objasniti posljedicom utjecaja nitratnog medija. Na osnovu iznesenih rezultata može se zaključiti da je mikrovalno rastvaranje uzoraka $\mathrm{u}$ nitratnoj kiselini pogodno za određivanje ukupnog arsena u zemljištu primjenom instrumenta SupraLab FD. Treba napomenuti da arsen u sastavu silikatne strukture neće biti detektovan, s obzirom da navedenim procesom mineralizacije ova frakcija arsena neće biti oslobođena.

\section{ZAKLJUČCI - Conclusions}

Na osnovu predočenih rezultata može se zaključiti sljedeće:

- razvijena je metoda za određivanje ukupnog arsena u zemljištu;

- metoda je zasnovana na redukciji arsenita ili arsenata u rastvoru amidosulfonske kiseline, te naknadnoj reakciji dobivenog hidrida arsena s živa(II) bromidom pri čemu se formira obojeni molekulski produkt čija detekcija se vrši spektrofotometrijski;

- metoda je primjenjiva za određivanje niskih koncentracija arsena, tj. može se korisititi za koncentracijsko područje arsena $0,2-20 \mu \mathrm{g} / \mathrm{dm}^{3}$;

- validacija metode je izvršena upotrebom referentnog materijala Montana Soil 2710 i interlaboratorijskom komparacijom, tj. paralelnom analizom uzoraka ICP-MS metodom;

- dobiveni podaci pokazuju da su odstupanja rezultata u dozvoljenim granicama za instrumente namijenjene za terenska određivanja;

- SupraLab FD je dobra alternative za skupe instrumente (ICP-MS, HG AAS), te se može koristiti za rutinska laboratorijska određivanja arsena u zemljištu po niskoj cijeni;

- koncentracija arsena u ispitivanim uzorcima tla ukazuje da se radi o kontaminiranom području s obzirom na visoke vrijednosti koncentracije mjerenog sadržaja arsena. Ovi rezultati se mogu smatrati preliminarnim, te ukazuju na mogući put daljih istraživanja.

\section{Zahvala-Acknowledgements}

Autori se zahvaljuju Ministarstvu za nauku i obrazovanje Republike Austrije, te WUSAustrija organizaciji na finansijskoj pomoći u realizaciji rada. Autori se takođe zahvaljuju prof. dr. Vladimiru Beusu na realizaciji i pomoći u prikupljanju uzoraka zemljišta za analizu. 


\section{LITERATURA - References}

AdRIANO, D.C. (1986): Trace Elements in the Terrestrial Environment. $1^{\text {st }}$ ed., Springer-Verlag, Berlin.

Aggett, J., AspelL, A.C. (1976): The determination of As(III) and total inorganic arsenic by atomic absorption spectrometry. Analyst, 101: 341-347.

AllowAY, B.I. (1995): Heavy Metals in Soils. $2^{\text {nd }}$ ed., Blackie Academic \&Professional, London.

BeRmAn, E. (1991): Toxic metals and their analysis. $2^{\text {nd }}$ ed., Heyden, London, UK.

CULLEN, W.R., ReIMER, K.J. (1989): Arsenic speciation in the environment. Chemical Reviews. 89 (4): 713-764.

DrieHAus W., JeKEL, M. (1992): Determination of As(III) and total inorganic arsenic by on-line pretreatment in hydride generation atomic absorption spectrometry. Fresenius' Journal of Analytical Chemistry, 343: 352-356

FRESENIUS, W., QUeNTIN, K.E., W. SchendeIR W. (1988): Water Analysis. 1st ed., Springer -Verlag, Berlin.

HASsWEel, S.J. (1991): Atomic Absorption Spectrometry. $1^{\text {st }}$ ed., Elsevier, Amsterdam.

Kabata-Pendias A., Pendias H. (1984): Trace Elements in Soils and Plants. $1^{\text {st }}$ ed., CRC Press Inc. USA.

Lopez, A., Torralba, R., Palacios, M.A., Camara, C. (1992): Generation of $\mathrm{AsH}_{3}$ from $\mathrm{As}(\mathrm{V})$ in the absence of $\mathrm{KI}$ as prereducing agent: Speciation of inorganic arsenic. Talanta, 39 (10): 1343-1348

Moderegger, H. (1998): Development of a New Device for the Determination of Arsenic. Master thesis. Karl-Franzens University, Graz, Austria.

NoRman, N.C. (1998): Chemistry of Arsenic, Antimony and Bismuth. $1^{\text {st }}$ ed., Blackie Academic \&Professional, London.

SCHENK, F. (1989): Quantitative Analytische Chemie. $4^{\text {th }}$ ed., Wieweg, Braunschweig.

Seiler, H.G., Sigel, A., Sigel H. (1994): Handbook on Metals in Clinical and Analytical Chemistry. Marcel Dekker, Inc., New York.

Shraim, A., Chiswell B., Olszowy, H. (2000): Use of perchloric acid as a reaction medium for speciation of arsenic by HG-AAS. Analyst, 125 (5): 949-953.

Stec, K., Bobrowski, A., Kalcher, K., Moderegger H., W. Goessler, W. (2006): Determination of Arsenic in Dolomites with a Simple Field Spectrometric Device. Microchimica Acta, 153: 45-49.

Torralba, R., Bonilla, M., Palacios, A., Camara, C. (1994): Flow injection and continuous flow system to determine arsenic species As(III) and $\mathrm{As}(\mathrm{V})$ by HG AAS. Anlusis, 22: 478-482 
WeLZ, B. (1998): Speciation analysis. The future of atomic absorption spectrometry. Journal of Analytical Atomic Spectrometry, 13: 413-417.

\section{Summary}

The aim of this work was to develop a simple and inexpensive method at low ppb levels for the determination of arsenic in soils. A device SupraLab FD was used for analysis, and it presents improved version of an instrument previously designed for the determination of inorganic arsenic in drinking water. A new analytical procedure was developed, and it is based on hydride generation of arsenic from acidic sample solution. Hydride generation of arsenic was performed with two tablets of amidosulfonic acid $(3,5600 \mathrm{~g}$ of pure acid) and one tablet of sodium borohydride $(0,300 \mathrm{~g}$ of borohydride in $5 \mathrm{~g}$ of sodium chloride matrix). The hydride formed during the reaction passed through filter paper, and reacted with mercury bromide giving a colored compound, which was optically detected. Optimization of experimental parameters was done with standard solutions of arsenite and arsenate, and calibration curves were established. A calibration plot fitted with quadratic function for concentration range of arsenic $0,2-60 \mu \mathrm{g} / \mathrm{dm}^{3}$ was obtained. Higher precision was observed for concentration range $0-20 \mu \mathrm{g} / \mathrm{dm}^{3}$ with following coefficients: $\mathrm{a}=$ $1,036 \cdot 10^{-3}, b=0,031$, and $c=-3,181 \cdot 10^{-4}$ with correlation factor of $r^{2}=0,9995$. The relative standard deviation (RSD) of signal decrease $(\Delta \mathrm{U})$ for $10 \mu \mathrm{gAs} / \mathrm{dm}^{3}$ was determined as $\pm 2,8 \%$ for $\mathrm{As}(\mathrm{III})$, and $\pm 2,6 \%$ for $\mathrm{As}(\mathrm{V})$. Limit of quantification was $0,2 \mu \mathrm{gAs} / \mathrm{dm}^{3}$, and the detection limit ( $3 \sigma$ value) was $0,06 \mu \mathrm{gAs} / \mathrm{dm}^{3}$.

Validation of the method was done by analysis of arsenic in forest soil samples applying a reference standard material (Montana Soil 2710), and interlaboratory comparison with ICP-MS method. The recoveries for the samples calculated according to data obtained with ICP-MS were between $92,0 \%$ and $95,0 \%$ which is in good agreement for the field device. 